

\title{
El usuario en el diseño, un significante a cuestionar
}

\author{
Jani Galland
}

En muchos campos de la actividad humana se nombra al usuario comúnmente, no obstante es en el campo del diseño donde su carácter mayormente es determinado. Esa figura móvil que representa a quién usará un objeto o servicio, pareciera tener una identidad oculta, pues al tratar de ver quién está detrás, no hay características definidas, como si de contemplar un vacío se tratara. Es casi obvio corresponder al usuario con una persona, animal o planta, pero definir con precisión quién es, resulta una aporía. El objetivo de este documento es hacer una revisión sobre el término dentro de sus características fundamentales, así como desentrañar su nacimiento dentro de la historia del diseño, para entender como un término que es usado indiscriminadamente dentro de ese campo designa a un humano, cuyo objetivo primario no es usar un objeto o servicio, sino existir.
In many areas of human activity, references to a user are commonly made; though it is mainly in the design field where his character is determined. However, the elusive figure that is supposed to use an object or a service seems to have a hidden identity. This may seem so because when we try to see who is behind it, we find no defined characteristics, and find ourselves in a void. It would seem obvious to match the term 'user' with a person, plant or animal, but to define with precision who he really is, is aporetic. The purpose of this paper is to review the fundamental aspects of this particular concept; unraveling its origins within design history in order to understand how a term that has been used indiscriminately within the field, designates a human whose main goal is not to use an object or service, but to exist. 
Siguiendo a Nietzsche las palabras no son sino "reproducciones fonéticas de impulsos nerviosos" y el lenguaje un sistema arbitrario de designación (Nietzsche 1873/1998 p. 20). El lenguaje, el medio que nos permite establecer un puente con la realidad como humanos y lo que nos diferencia de las demás especies, aun cuando continuamente deviene estableciendo nuevos paradigmas -resultado de la relación que guardamos con el contexto y con nuestros semejantes- guarda un límite móvil, ya que aun cuando se expande al crear nuevas formas de designar a la realidad, también se fijan dichos designios a través de la mitificación de conceptos que surge a partir de un evento indeterminado o determinado y que hasta mucho tiempo después -en el mejor de los casos- es cuestionado o queda en desuso cuando el evento sale del imaginario colectivo, es decir cuando su significado no contribuye con la realidad en un tiempo dado. ${ }^{1}$

Aquello que denominamos de una u otra forma podría sólo pertenecer al mundo de las palabras y limitarse a ello, a lo que se queda en el registro escrito o se comunica con sonidos, sin embargo es a través de los registros escritos, de lo que se comunica de boca en boca, que se construye una realidad compartida, que se acerva a modo de historia en los libros. Pero más allá de la cultura y sus constructos, lo que subyace en el fondo de la comunicación es la determinación de una conducta asumida y la respuesta que empleamos ante la comprensión tácita —en la gran mayoría de los casos- de un concepto, que además puede cobrar múltiples significados ya que hablamos sin reflexionar concienzudamente en lo que decimos, cómo lo decimos y lo que tratamos específicamente de expresar; si no estamos conscientes plenamente de aquello que hemos elegido para que forme parte de nuestro sistemas de creencias, y parte de nuestro pensamiento; menos aún de toda la información que albergamos sin cuestionarla.

Lacan efectúa el pasaje de las leyes de la palabra a las leyes del lenguaje. Este viraje es de crucial importancia ya que ubicará la metáfora y la metonimia como leyes del inconsciente. Esto llevará al deseo como metonimia y no como deseo de reconocimiento, lo que marcará el pasaje, por parte del analista, de reconocer el deseo a interpretarlo (Tizio Domínguez, 1990, p.200).

El presente trabajo responde a una inquietud que vincula al diseño con el campo de la antropología, y la psicología. El objetivo de este texto es aplicar una metodología fenomenológica para develar la construcción del usuario dentro de la historia del diseño, así como las relaciones que se forma a partir de su ser. Por otro lado se intenta poner al descubierto la confección mítica del usuario, desde una perspectiva antropológica en dos sentidos, en primera instancia desde la disciplina en su campo integral y por otro lado de forma particular comprendiendo además su semántica, desde una visión lingüística así como haciendo un análisis desde la visión lacaniana que permita observar como una palabra no sólo designa sino que genera un sinfín de fenómenos en dónde el inconsciente juega un papel muy importante, pues responde a las improntas que el mundo del consumo nos impone. Por

1. Tal es el caso del escribano, cuya función en la sociedad moderna ya no tiene una función real, to interesante es hacer notar como tanto el oficio como la palabra quedan en desuso y por ende fuera del imaginario colectivo. Escribano: Funcionario público autorizado para dar fe de las actuaciones judiciales y que antiguamente desempeñaba también las funciones notariales. (D.R.A.E.) 
último, a modo de conclusión el intento es por crear conciencia sobre el término dentro del campo del diseño - tanto en la práctica como en la formación disciplinar del diseñador-con el fin de propiciar una reflexión antes de volver proponer una nueva solución o diseñar, pensando que en el mejor de los casos el diseño en algún momento se centre en el humano.

De este modo comenzaremos por entender algunas generalidades del término humano y su definición desde la instancia antropológica, después desarticularé el contexto en qué nace el usuario en el campo del diseño ${ }^{2}$ y por último se abordará la esfera lingüística.

\section{La antropología y el usuario}

Es necesario y suficiente que el cuerpo que veo y su palabra que oigo, y que me son dados inmediatamente presentes en mi campo, me presenten a su modo aquello a lo que nunca estaré presente, que siempre me será invisible y de lo que nunca seré testigo directo (Ponty, 1964, p. 114).

Al preguntarme -partiendo del yo como intérprete y como instancia fenomenológica hablo desde mí, y en epojé (suspensión del juicio)- ¿quién es el usuario? lo primero que vino a mi mente fueron una serie de supuestos sinónimos inmediatos: hombre, humano, sujeto, individuo. Debido a que la connotación genérica a la que evoca el empleo del término hombre, decidí irme por el cuestionamiento del humano y del sujeto - en tanto a supuestos sinónimos- dejando para otra discusión al individuo. Asimismo me resultó obvio utilizar a la antropología como uno de los focos más pertinentes para hablar sobre el humano, ya que no sólo da cuenta de él sino de lo que produce, y en este sentido es que la pertinencia de la ciencia dentro del campo del diseño no solo es evidente sino fundamental y la relación de análisis que se suscita en torno al usuario, además de interesante dentro de esta discusión, es un parámetro que permite esbozar de una forma más contundente el significante del usuario en función del humano.

Para abordar al usuario desde el campo antropológico -aun sabiendo que dicho término sólo cobra referencias tangencialesabordaré al humano y al sujeto en primera instancia por ser términos más precisos dentro de este campo, ya que además es fundamental entender desde qué punto de vista esta disciplina lo definen - a pesar de la evidente carencia de parámetros estrictos- desde sus diversas perspectivas y obedeciendo a la respuesta sinónima como la que comencé. Así pues el humano es aquél primate homínido, con capacidad de razonamiento, un ser social al que se le estudia desde sus relaciones parentales, culturales, económicas y políticas, al mismo tiempo que el modo en el que establece una comunicación con su entorno es otro lente, y por último el estar en un contexto determinado es otro objeto de estudio.
Cuando usamos el término humano, marcamos una referencia a la especie, así como al denominar al ser humano, hablamos en tanto a la experiencia, pero al mismo tiempo y en ambos casos, aludimos a un ser que en su confección mantiene una relación con los otros - de su misma especie y de otras- pero que presenta características que lo sujetan a una percepción singular y que a través de la voluntad traza del mismo modo un camino que responde a esa singularidad y no a otra.

El ser humano implica ante todo un ser y estar de un modo determinado en la tierra, y una comunión continua entre la percepción y lo percibido, así en tanto a la alteridad (Ponty, 1964). Dentro de ese habitar cotidiano es que el ser humano en su condición de sujeto establece una dialéctica entre su mundo interno y externo, estableciendo puentes de comunicación, a través de objetos con los cuales cumplirá con los dos objetivos fundamentales de su existencia: sobrevivir y preservar la especie mediante la adaptabilidad que logre mantener a lo largo de su ciclo de vida y los mecanismos que desarrolle para cumplir con dichos objetivos.

Ahora, abordando de nuevo al usuario, me valgo de las definiciones y tenemos que un usuario no es un humano o sujeto, y por otro lado un sujeto no es un objeto. Analizando en primera instancia la dialéctica y dupla que se genera entre el sujeto y el objeto, como algo que se constituye mutuamente, por un lado, el sujeto representa al ser humano como un ser, que bien de forma amplia evoca a su entera naturaleza (desde el aspecto biológico, social y cultural) y que de un modo estricto alude a su mundo interior. Si el sujeto no es el objeto -en este caso más bien es antítesis del objeto- por ende el objeto se encuentra fuera de él, y no es él, aun cuando se constituyen en tanto a la percepción que tiene el sujeto en tanto al objeto, y al mismo tiempo al ser el sujeto en tanto a una sociedad determinada, también se constituye como un objeto, no obstante la aparente aporía el sujeto no es un objeto ${ }^{3}$ por denotación, aunque su connotación y relación con el mundo lo hagan danzar de un lado al otro -Aunque en el campo de la filosofía tradicional, específicamente en el modelo del cogito cartesiano, la problemática de la alteridad lo suponen como un objeto en tanto al sujeto que lo percibe y que no es él mismo, el modo en el que describo al sujeto en este apartado responde a la visión de alteridad presente en el trabajo tanto de Merleau Ponty, como de Levinas-. En segunda instancia la denotación del usuario, es un término que nace a partir de una acción -la del uso- y que no alude directamente al humano, aún si tomamos en cuenta que el ser humano ontogénica $-Y$ en este caso el sentido ontogenético en sus primeras etapas no alude a una relación con

2. Usuario al que marcaremos a lo largo de este texto como referencia particular, sin dejar de lado que puede o no ser similar e incluso el mismo dentro de otro ámbito o campo de conocimiento humano.

3. "(...) vacío trono del sujeto sentado en él el objeto no sería más que un ídolo." (Adorno, 1984, p.185) 
un objeto sino con un espacio que le es propiciado dentro de la madre, espacio que usa para desarrollarse- y filogénicamente es un ser que usa. El usuario entonces no es más que una conjugación de ese concepto con respecto al ser humano, un concepto en dónde ciertos parámetros de un sujeto pueden ser encontrados, pero nunca como un ser con procesos cognitivos, no como un sujeto, no en el sentido amplio, ni en el estricto, sino como una posibilidad en dónde una o más características de un humano - o varios a la vez- pueden ser contenidas. El usuario se convierte en una más de las cosas que se encuentran fuera del humano, del sujeto, pero que no es el otro sujeto, es un objeto, un producto del hombre, un fenómeno en dado caso.

\section{El nacimiento del usuario a partir de la era industrial}

El diseño, como actividad creativa ha estado presente como medio expresivo en el ser humano (Polya, 1973), siendo la capacidad de llevar un problema o situación determinada a una condición diferente en dónde se observen más beneficios que en la etapa inicial, en consecuencia además del medio circúndate. Este tipo de actividad y pensamiento, fue una de las respuesta a las necesidades que la Revolución Industrial generó, era preciso que un grupo de personas desarrollaran habilidades específicas, que le permitieran a la industria por un lado hacer más eficientes las líneas de producción y por otro lado generar un mejor vínculo entre el producto y el consumidor final (Salinas, 1992). Este tipo de especialistas no eran obreros, tampoco ingenieros, ni estaban en el campo del arte, no obstante su labor tenían como fin proponer las mejores condiciones posibles entre un objeto con objeto me refiero específicamente a lo que no es el sujeto, puede ser tangible, intangible como un servicio, su contexto y para quién estaba designado el mismo. El pensamiento en sus características generales debía atender de forma contundente fundamentalmente los aspectos de producción, función, ergonomía y formales, relacionando todo esto con un usuario y su contexto. Es de esta forma que poco a poco el diseño, una actividad que conjuntaba la creatividad, con una sociedad moderna y las recientes propuestas de producción en serie, comienza a ser un campo disciplinar temprano en Europa, Estados Unidos, cuya cúspide mítica estaría representada por la Bauhaus en Alemania - la casa de la construcción- en dónde se atendían expresiones relativas al medio del diseño, entre ellas el diseño industrial; aun cuando el diseño industrial centra su atención en el usuario, cabe mencionar que las demás expresiones como la arquitectura y el diseño gráfico -entre otras-de alguna forma también lo hacen, sin embargo tomaremos como punto de partida al diseño industrial, para circunscribir al usuario dentro de este medio disciplinar. A partir de este momento sólo había un objetivo aparente: que el good design estuviera centrado en satisfacer a toda costa las necesidades del usuario, mientras al mismo tiempo las líneas de producción trabajaran cada vez más de un modo más eficiente.
El usuario (Ilamado también hombre de la calle, y cuyo conjunto recibe el nombre inocente de población; ya hemos visto todo esto en el vocabulario del señor Macaigne), el usuario es un personaje imaginario, algebraico se podría decir, gracias al cual se hace posible romper la dispersión contagiosa de los efectos y mantener firme una causalidad reducida, acerca de la cual se podrá razonar tranquila y virtuosamente. (Barthes, 1980, p.75).

Es en este medio donde nace el usuario como un destinatario, quien por un lado gozaría de las ventajas de la producción en serie, la modernidad y el confort resultado del minucioso trabajo de los diseñadores. Sin embargo con esto también nace el que elige de forma directa o indirecta la compra del producto o servicio, el diseño gráfico sin duda, juega un papel fundamental en la promoción publicitaria de los productos, la mercadotecnia poco a poco empieza a evolucionar, todo marcha sobre ruedas. El usuario se convierte en un modelo ideal para una solución fantástica, es móvil, puede designársele cualquier atributo, siempre y cuando exista aquél que pueda elegir la compra, el usuario es el comprador ideal, es la gasolina de todas las industrias, sin él nada funcionaría.

Es claro que en un inicio uno de los objetivos primordiales del diseño era satisfacer las necesidades del usuario de la mejor forma posible, sin embargo al curso del tiempo, el objetivo de las industrias, de los productores, era generar cualquier necesidad que pudiera ser elegida de alguna forma o de otra por un usuario, el usuario comienza a diseñarse, a confeccionarse, se crean objetos que puedan encajar bien en las características estereotipadas de los usuarios diseñados, el usuario comienza a ser un campo dónde los humanos llenos de deseos en el afán por una vida más cómoda persigue las fantasías que otros crean para él.

\section{Semántica y semiótica del término usuario}

Una vez claro de modo general y sin duda superficial sobre el nacimiento del término usuario a partir en la Historia del Diseño, y la naturaleza del mismo como producto del humano, ahora veamos qué es lo que usuario, como palabra, concepto y mito propone. Al ser una disertación lingüística podría haberse abordado dentro de la esfera antropológica, sin embargo es la constitución del lenguaje un apartado que merece ser revisado posteriormente al estado de arte del término dentro del campo del diseño y que además tiene un enfoque psicológico.

El ser humano a lo largo de la historia ha establecido diversos parámetros para que los lenguajes sean comprendidos por un grupo de personas en un sentido uniforme, de este modo es que se construyen los idiomas y las hablas, modelando la manera en la que se percibe la vida a través de una noción común 
gráfica y sonora. El modo en el que nos expresamos alude a un sinfín de significantes y significados, y es únicamente cuando tenemos un intérprete con quién dialogar que nuestros pensamiento toman forma, en tanto al otro, en tanto al contexto pero también en tanto a nosotros mismos.

(...) es anterior e independiente del sujeto. Pero engendra el sujeto en el viviente. El sujeto nace en el hombre por la intervención del lenguaje sobre el organismo, no hay sujeto antes del lenguaje. A su vez, engendra la dimensión del Otro. El Otro del lenguaje es, según Miller, la oposición significante misma, el hecho de que si hay un significante 1, hay un significante 2, si hay uno, hay Otro, esto es por definición de la estructura del lenguaje. (Negro, 2009, p. 6).

De esta forma es que aquello que comunicamos, la forma en que nos relacionamos con los otros y con la realidad que percibimos es una dialéctica entre lenguaje y alteridad contenida en un contexto determinado. Si el lenguaje es un puente entre nuestra percepción sobre la vida, esta percepción además de contener todo aquello que nuestra propia historia como humanos relata -aunada además a la realidad del otro de los otros y el contexto en el que nos desarrollamos- no sólo las palabras que emitimos tienen una dirección superficial que pueda o no ser comprendida por el otro, en su significado obvio, sino que además contienen nuestra propia impresión sobre la vida, lo cual incluye todo aquello que tenemos de presente de modo es decir como parte de nuestro consciente, pero también todo aquello que pertenece al inconsciente.

Como menciona Lacan, el inconsciente se estructura como un lenguaje (Lacan, 2009) que está compuesto por palabras tan comunes como usuario, y es a partir de esta premisa que el usuario -como término, como palabra y concepto- posee una mayor profundidad que la que aparentemente opera en este caso dentro del campo del diseño, la publicidad y la mercadotecnia, pues reduce una realidad como lo es la vida de un humano a una mentira (Lacan 2009), señalando únicamente lo que no es, dejando de lado todo lo que es.

La palabra es la que instaura la mentira en la realidad. Precisamente porque introduce lo que no es, puede también introducir lo que es. Antes de la palabra nada es ni no es. Sin duda, todo está siempre allí, pero sólo con la palabra hay cosas que son -que son verdaderas o falsas, es decir, que son-y cosas que no son. Solo con la dimensión de la palabra se cava el surco de la verdad en lo real. (Lacan, 1996, p. 133).

Cada disciplina refiere a un sinfín de términos que promueven no solo palabras con un significado específico, sino medios comunes formados a partir de una o más palabras, es decir un concepto que cerca lo que es relativo a un tipo de conocimiento en específico. Así, algunos de los conceptos serán comprendidos únicamente dentro del gremio o con los afines, mientras algunos otros trascenderán las fronteras de las disciplinas, extendiéndose incluso a las esferas cotidianas formando parte del imaginario colectivo, amoldando la percepción dentro y fuera del campo del conocimiento, expandiéndose hasta el punto en el que una palabra es comprendida en su sentido estricto, pero también logra vincularse con un concepto determinado. Este es el caso del usuario dentro del campo del diseño que por ahora - aun cuando la publicidad y mercadotecnia permanecen vinculadas- es el que nos compete.

Toda la mecánica del conocimiento es un aparato de abstracción y de simplificación, que no está encaminado al conocer, sino a conseguir poder sobre las cosas: el "fin" y el "medio" están tan alejados de la esencia como los conceptos. Con "fines" y "medios" nos apoderamos del proceso (se inventa un proceso que es palpable), pero con "conceptos" de las "cosas" que forman el proceso (Nietzsche, 1996, p. 284).

Como resultado de una búsqueda superflua dentro de las primeras imágenes que pueden encontrarse al teclear en español usuario, en ingles user y en alemán Benutzer encontramos un ícono que representa a una persona sin particularidades develadas. El usuario es un ente que en algunos casos representa un género, pero que no simpatiza con alguna religión o creencia, que tampoco evoca a una peculiaridad racial y que se asemeja a un receptáculo cuya definición está en un vínculo estrecho con su medio inmediato.

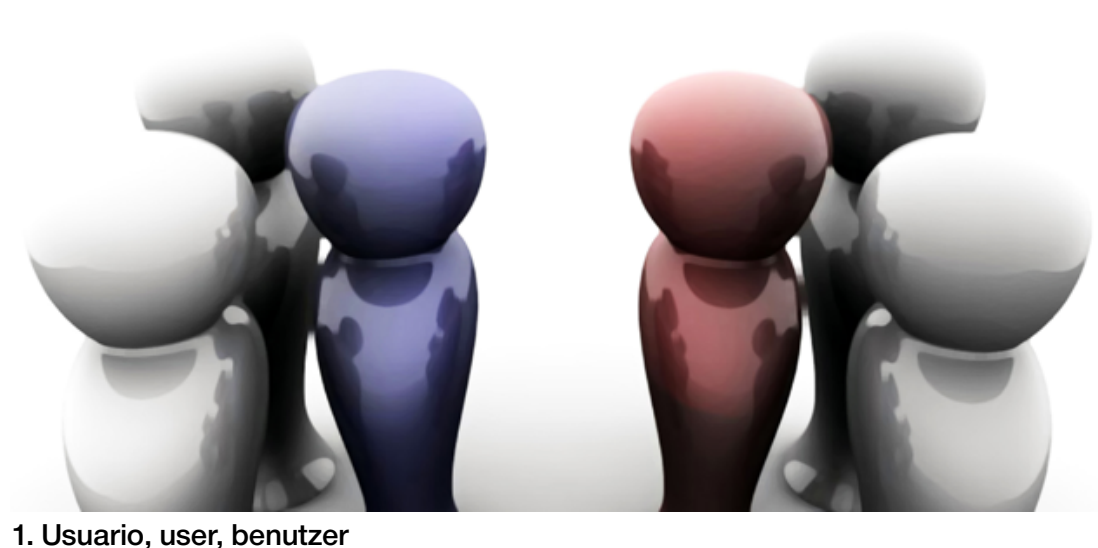

1. Usuario, user, benutzer

En este punto es dónde el usuario es un término muy interesante y al mismo tiempo clave, ya que aún cuando la imagen que propicia en la imaginación no tiene características definidas, y el significado, el significante y el referente evocan a algo parecido a un vacío, este vacío ha sido propiciado para permanecer en esta posición hasta que un contenido le sea asignado - es decir sea diseñado- y de este modo producir una imagen artificial que empatará en un contexto también artificial que estará listo para 
ser vendido. El usuario claramente tiene un contenido que es producido minuciosamente, dentro de la práctica del diseño.

De la semántica de la palabra y partiendo del español, la definición que la R.A.E. hace al respecto -entendiendo que aún cuando las raíces de la palabra pueden variar de una lengua a otra- el sentido es el mismo:

Usuario, ria. (Del lat. usuarius).

1. adj. Que usa ordinariamente algo. U. t. c. s.

2. adj. Der. Dicho de una persona: Que tiene derecho de usar de una cosa ajena con cierta limitación. U. m. c. s.

3. adj. Der. Dicho de una persona: Que, por concesión gubernativa o por otro título legítimo, goza un aprovechamiento de aguas derivadas de corriente pública. U. t. c. S. (RAE, 2014).

En la primera definición como adjetivo se alude a quién usa algo, esto sin mencionar si se está hablando de una persona, animal o cosa, en la segunda y tercera nos encontramos con una referencia directa a la persona. Asimismo el sentido estricto de la palabra, un usuario es el que usa, sin embargo su definición no deja al descubierto quién está detrás de esta figura.

\section{Conclusiones}

El usuario es una forma de denominar al humano en una condición de uso determinada y a un sujeto con alguna peculiaridad definida, la cuestión surge cuando nos preguntamos quién es ese usuario y ¿por qué se diseña para un usuario y no para un humano (o sujeto en una alusión más específica)?, por otra parte ¿qué problemática representa el no diseñar para un humano y continuar pensando en un usuario a la hora de generar soluciones?

El usuario al ser designado representa una posibilidad humana pero estructurada, definida para su venta, quizá cobre un matiz que represente algún género, alguna condición económica e incluso política, el usuario se convierte en un agente que dirige la industria del consumo y al ser evocado es comprendido por el auditorio de alguna forma determinada, vislumbrándolo como algo finito que puede ser definido dentro de un contexto determinado y no en otro. Aun cuando el usuario puede pisar dos - o más- escenarios designados para dos usuarios diferentes, pero similares, e incluso jugar con las variables de la combinación de escenarios, el usuario supone movimientos fijos, previstos, diseñados, designados, si bien voluntades impuestas, nunca elecciones que respondan a una de las características primordiales del ser humano, su estado de autenticidad único e irrevocable.

Ahora bien, después de haber repensado la diferencia antropológica entre humano y usuario, haciendo un breve recorrido histó- rico por el nacimiento del término en la era industrial, cuestionando su semántica y entendiendo la importancia de las palabras que usamos y como las usamos desde el lente de la psicología en conjunción con la lingüística, podemos enfatizar la importancia de hacer un uso consciente de los términos que empleamos al ejercer nuestras profesiones. No sólo por la pertinencia de los términos en tanto a las formas, sino por el impacto inconsciente que las palabras crean.

En las etapas más tempranas del campo del diseño, se asignó el término a quién o quienes representan el centro de una problemática dada, el usuario, el que determina el uso de un producto -entendiendo como producto lo tangible pero también lo intangible. El usuario más allá de ser una palabra que puede evocar lo mismo a un significante que a un significado es un concepto que se desdobla cuando toma acción, cuando se convierte en verbo y que no solamente funciona como un medio para designar sino que genera una serie de fenómenos que bien vale la pena revisar en busca de generar un nuevo parámetro a la hora de pararnos frente a una problemática entendiendo que aquello que concebimos como diseño no puede estar enfocado únicamente en el uso o la función, sino que es fundamental entender que aquél para el que diseñamos no es un simple usuario, sino un humano en experiencia, con toda la complejidad que ello implica y que se desborda más allá del uso, tirando los límites en dónde las emociones, las reflexiones y la vida cobran sus matices.

Si al ubicarnos como diseñadores frente a una problemática determinada -como ese pulso común de querer rediseñar una silla- lo hacemos colocando en nuestro proceso creativo a un humano en lugar de a un usuario, pensaremos no solamente en los aspectos productivos, funcionales, formales o ergonómicos, eso lo haremos de modo automático debido a que en nuestro pensamiento se encuentra inscrito dicho tipo de análisis. Lo interesante al hacer el ejercicio mental son una serie de focos -en un sentido metafórico- que le darán luz a las imágenes de proyección y cuestionantes como ¿quién es ese humano? -convirtiéndolo entonces en sujeto- qué posee una característica esencial que no tiene ninguno otro, y aunado a los supuestos qué experimentar en su relación con ese objeto, sin duda el resultado iría más allá de la confección de un objeto y se situaría más en ese elemento compasivo de articulación que desarrollamos como humanos cuando intentamos - solo en un supuesto y por un muy breve tiempo- qué es eso que siente el otro, que si bien es otro y no soy yo, pero que se encuentra en una experiencia humana lo mismo que quién está creando dicho objeto y cuya importancia promueve la preservación de nuestra especie y por ende el contexto en el que existimos.

A pesar de ser el usuario un recipiente perfecto para confeccionarlo como un tipo de modelo o prototipo que pueda satisfacer 
diversos tipos de necesidades y entendiendo que uno de los objetivos primordiales del diseño -en todas sus dimensiones y campos de estudio-así como de otras disciplinas que convergen con él, es generar las mejores posibilidades en tanto al usuario procurando su bienestar y el común, el entender que ese usuarioun ente imaginario- creado por un humano, no es un humano, abren una posible vía en tanto al diseño, pero también en tanto a nosotros como humanos, para vivir en una realidad que nos permita expresar eso que cada uno de nosotros tenemos y no tiene nadie más, al mismo tiempo esto propiciaría en su ejercicio consciente y dejando espacio para ello, que existieran las condiciones para que la expresión heurística de cada sujeto, se ejecute. No somos usuarios que atravesamos las experiencias que diseñan para nosotros, poseemos no sólo una piel que busca tersura, ni músculos que pretendan relajarse en todo momento para desplazarse de un momento a otro sin esfuerzo alguno por parte de ellos. En lugar de eso somos una especie que razona, percibe, siente y expresa, con una creativa latente de modo permanente.
Quizá un punto de partida, el grano de arena con el que el diseño puede colaborar y una de las vías que propician este tipo de cambios que en más de un sentido evocan a la toma de consciencia sobre nuestra existencia, es la difusión del trabajo teórico a través de la reflexión aunada a la investigación. El camino por recorrer no es corto y el impacto de este tipo de aportaciones solo se irá inscribiendo en tanto quien lea, critique o cuestione este texto, colaborando en la expansión de esta discusión y afines, así como en una práctica más consciente.

La única experiencia que nunca podremos tener es la del otro, el otro es lo que no somos nosotros, pero al mismo tiempo constituye la posibilidad única de mirarnos a nosotros mismos en tanto a su presencia. De ahí la importancia del otro, y en el caso del diseño a lo que se enfrenta en el ejercicio de su actividad, diseñar para otro, tratando utópicamente de entender su posible experiencia. Esto como última reflexión, una situación que el diseño puede abordar desde los confines creativos de su expresión.

\section{Referencias}

ADORNO, T. W. (1984). Dialéctica negativa.

Madrid: Taurus Ediciones.

BARTHES, R. (1980). Mitologías. México D.F.:

Siglo ventiuno editores S.A. de C.V.

BAUDRILLARD, J. (1969). El sistema de los objetos.

México D.F.: Siglo XXI.

Real Academia de la Lengua Española. (2001). Usuario, Diccionario de la Real Academia de la Lengua Española, 22 $2^{a}$ edición, Recuperado de: http://lema.rae.es/drae/?val=usuario

LACAN, J. (1996). El Seminario. Libro 1. Buenos Aires: Paidos.

(2009). Seminario 17, el reverso de psicoanálisis.

Buenos Aires: Paidós.

NEGRO, M. A. (2009). Lenguaje, palabra y discurso en la enseñanza de Jaques Lacan. Revista Affectio Societatis, 6.
NIETZSCHE, F. (1996). Ecce Homo.

Madrid: Alianza.

(1998). Sobre verdad y mentira en sentido extramoral. Madrid: Tecnos. Texto original publicado en 1873.

POLYA, G. (1973). How to solve it. New Jersy: Princeton University Press.

PONTY, M. M. (1964). Le Visible et l'invisible. Paris: Gallimard. Salinas Flores, O. (1992). Historia del Diseño Industrial. México: Trillas.

TIZIO DOMÍNGUEZ, H. M. (1990). Psicoanálisis y lenguaje. La aportación original de Jacques Lacan. Barcelona: Universitat de Barcelona. 